\title{
ANALISIS KOMPARATIF KELAYAKAN USAHA AGROINDUSTRI DODOL PADA BERBAGAI VARIAN RASA DI UD. WARNA SARI DESA SURANADI KECAMATAN NARMADA KABUPATEN LOMBOK BARAT
}

\author{
I NENGAH CANDRA DEWANA ${ }^{1),}$ MADE SUMA WEDASTRA ${ }^{2),}$ \\ I GUSTI NGURAH ARYAWAN ASASANDI I), I DEWA GEDE SUARTHA ${ }^{4)}$
}

\author{
${ }^{1)}$ Mahasiswa, ${ }^{2,3,4)}$ Dosen Program Studi Agribinis K. Mataram UNMAS Denpasar \\ 1)Chandrateknik9@gmail.com, 2)madesumawedastra17@gmail.com, \\ 3) arya.sandi.as@gmail.com, ${ }^{4)}$ dsuartha@ymail.com
}

\begin{abstract}
ABSTRAK
Penelitian yang berjudul analisis komparatif kelayakan usaha agroindustri dodol pada berbagai varian rasa di UD. Warna Sari Desa Suranadi Kecamatan Narmada Kabupaten Lombok Barat, telah dilaksanakan, secara purposive sampling dengan pertimbangan bahwa pada UD. Wanasari, memiliki masalah tentang kelayakan usaha dan diberikan ijin untuk melaksanakan penelitian. Teknik pengumpulan data yang digunakan adalah dengan observasi, wawancara dan dokomentasi, sedangkan alat yang digunakan pada penelitian ini adalah denan menggunakan kuistioner. Kemudian analisis data menggunakan analisis biaya dan keuntungan, $\mathrm{RC}$ ratio, $\mathrm{BC}$ ratio dan $\mathrm{BEP}$

Hasil penelitian menunjukkan bahwa : agroindustri dodol yang paling besar keuntungannya dan layak untuk diusahakan per bulannya adalah agroindustri dodol varian rasa nangka, dengan keuntungan rata-rata keuntungan diperoleh per bulan sebesar Rp. 3.447.500, dan perolehan $\mathrm{R} / \mathrm{C}=30,45, \mathrm{~B} / \mathrm{C}=10,24$, lebih tinggi dari pada agroindustri dodol varian lain dengan titik impas (BEP volume) $=121,8$ mika dan BEP nilai penjualan $=$ Rp. 508.470,07. Varian dodol semua rasa menguntungkan dan layak untuk diusahakan, karena RC ratio, BC ratio > 1, sehingga disarankan kepada pemilik UD. Wanasari, Desa Suranadi Kecamatan Narmada Kabupaten Lombok agar tetap membuat dodol dengan berbagai varias rasa, untuk menarik minat konsumen berbelanja ke usaha dagang tersebut.
\end{abstract}

Kata kunci : analisis komparatif, keyakan usaha, varian rasa

\section{ABSTRACT}

The study, entitled comparative analysis of the feasibility of the dodol agro-industry business on various flavors at UD. Warna Sari Suranadi Village, Narmada District, West Lombok Regency, has been implemented, by purposive sampling with the consideration that at UD. Wanasari, had problems regarding business feasibility and was given permission to carry out research. The data collection techniques used were observation, interviews and documentation, while the tools used in this study were questionnaires. Then the data analysis used cost and benefit analysis, $R C$ ratio, $B C$ ratio and $B E P$

The results showed that: the dodol agro-industry which had the greatest profit and was feasible to operate per month was the jackfruit flavored dodol agro-industry, with an average profit of Rp. 3,447,500, and the acquisition of $R / C=30.45, B / C=10.24$, higher than the other variant dodol agroindustry with break-even point $(B E P$ volume $)=121.8$ mica and BEP sales value $=R p .508,470.07$. All dodol variants taste profitable and worth working on, because the $R C$ ratio, $B C$ ratio is $>1$, so it is recommended to the owner of UD. Wanasari, Suranadi Village, Narmada District, Lombok Regency, to keep making dodol with various flavors, to attract consumers to shop at the trading business.

Keywords: comparative analysis, feasibility study, flavor variants 


\section{PENDAHULUAN}

\section{Latar Belakang}

Pengembangan agroindustri merupakan salah satu upaya dalam meningkatkan nilai tambah produk hasil pertanian serta mengubah sistem pertanian yang semula masih sederhana menjadi lebih maju atau modern melalui penerapan teknologi terbaru, sehingga bisa lebih mudah melakukan pengolahan produk buah manjadi dodol. Dengan adanya pengolahan (agroindustri) buah tersebut, maka dapat ditawarkan bahan pangan sesuai selera konsumen dan mempunyai daya simpan yang lama, (Widyastuti,1993).

Dodol merupakan salah satu jenis makanan tradisional yang sudah populer. Di beberapa daerah terutama ditempat wisata. Makanan ini tergolong dalam makanan berbentuk semi basah. Selain itu, makanan ini juga memiliki sifat organoleptik yang khas, seperti warna coklat, rasa manis, tektur yang lengket seperti adonan liat, serta aroma yang khas sesuai dengan bahan baku yang digunakan.

Pengolahan buah menjadi dodol merupakan salah satu upaya untuk memperpanjang daya simpan buah dan menciptakan nilai tambah terhadap hasil pertanian tersebut. Pada awalnya dodol digunakan pada perayaan hari besar seperti hari raya keagamaan, perkawinan, kelahiran dan sebagainya. Akan tetapi, saat ini dodol dipasarkan meluas, terutama ditempat parawisata dengan kemasan yang menarik, sehingga dodol dengan berbagai varian rasa dapat dipakai sebagai oleh-oleh bagi wisatawan, dan permintaan dodol mengalami peningkatan (Sugiyono dalam Gizka, 2012).

UD. Wanasari merupakan salah satu perusahaan yang mengolah buah-buahan segar menjadi dodol. Dengan adanya pengolahan (agroindustri) buah tersebut, maka ditawarkan varian rasa sesuai dengan selera konsumen dan mempunyai daya simpan yang lama.

Sampai saat ini UD.Wanasari untuk melayani dan meningkatkan pemintaan konsumen, Selain membuat dodol varian rasa nangka juga membuat dodol rasa sirsak, pisang, durian dan ketan hitam. Untuk jelasnya produksi dodol tersebut dapat dilihat pada Tabel 1.

Tabel 1. Data Penjualan Dodol di UD. Warna Sari per bulan Tahun 2017-2019

\begin{tabular}{|c|l|l|l|l|l|l|}
\hline \multirow{2}{*}{ Tahun } & \multicolumn{6}{|c|}{ Varian Dodol } \\
\cline { 2 - 7 } & & \multicolumn{1}{|c|}{ Nangka } & \multicolumn{1}{c|}{ Sirsak } & \multicolumn{1}{c|}{ Pisang } & \multicolumn{1}{c|}{ Durian } & Ketan Hitam \\
\hline \multirow{2}{*}{2017} & 1 & 136 & 112 & 150 & 60 & 105 \\
\cline { 2 - 7 } & 2 & $6,800,000$ & $5,600,000$ & $7,500,000$ & $4,200,000$ & $6,300,000$ \\
\hline \multirow{2}{*}{2018} & 1 & 119 & 100 & 140 & 55 & 110 \\
\cline { 2 - 7 } & 2 & $5,950,000$ & $5,000,000$ & $7,000,000$ & $3,960,000$ & $7,260,000$ \\
\hline \multirow{2}{*}{2019} & 1 & 130 & 106 & 120 & 74 & 100 \\
\cline { 2 - 7 } & 2 & $6,500,000$ & $5,300,000$ & $6,000,000$ & $5,032,000$ & $6,000,000$ \\
\hline \multirow{2}{*}{ Rata-rata } & 1 & 133 & 106 & 132 & 63 & 105 \\
\cline { 2 - 7 } & 2 & $6,650,000$ & $5,300,000$ & $6,600,000$ & $4,410,000$ & $6,510,000$ \\
\hline
\end{tabular}

Sumber : UD. Wana Sari (2020)

Keterangan : $1=$ produksi dalam $\mathrm{kg} / \mathrm{bulan}, 2=$ Nilai produksi dalam rupiah

Dari Tabel 1 di atas dapat dijelaskan bahwa produksi dan harga dodol dari tahun 2017 sampai dengan tahun 2019 berpluktuasi, dimana dodol yang paling banyak dibuat adalah dodol nangka, kemudian berturutturut diikuti oleh dodol pisang, sirsak, ketan hitam dan yang paling sedikit adalah dodol durian.

Banyak sedikitnya dodol yang dibuat oleh UD.Wanasari tergantung pada tersedianya bahan baku dodol dan jumlah permintaan konsumen. Semakin banyak tersedianya bahan baku, maka semakin banyak juga dodol yang diproduksi. Demikian juga harga dodol, biasanya jika tersedianya bahan baku sedikit, maka harga bahan baku lebih mahal, sehingga harga produksi juga naik. Walaupun tidak selamanya demikian, tetapi bisa juga walaupun harga bahan baku meningkat, namun pihak perusahaan tidak menaikan harga jualnya, tetapi ukuran dodolnya yang diperkecil.

Tabel di atas juga menunjukkan bahwa nilai produksi dodol yang paling tinggi adalah dodol nangka, kemudian berturut-turut diikuti oleh dodol pisang, sirsak, ketan hitam dan yang paling kecil nilai produksinya adalah dodol durian. Tinggi rendahnya nilai produksi dodol disebabkan oleh jumlah produksi lama berproduksi dan harga produksi yang berbeda

Dari segi produksi dan nilai produksi pada masin-masing dodol berpluktuasi baik dari segi produksi, harga dan nilai produksi. Perbedaan produksi dan nilai produksi tentu berhubungan dengan biaya-biaya yang dikeluarkan selama proe produksinya. 
Besar-kecilnya biaya yang dikeluarkan akan mempengaruhi keuntungan perusahaan, dan besar kecilnya keuntungan perusahaan akan mempengaruhi kelayakan usaha. Oleh karena itu analisis kelayakan usaha bagi setiap perusahaan sangatlah penting.

\section{Rumusan Masalah}

Dari uraian di atas, dirumuskan pemasalahannya adalah dodol varian rasa apakah yang paling menguntungkan dan layak untuk diusahakan

\section{Tujuan dan Manfaat Penelitian}

Tujuan dari penelitian ini adalah : untuk menganalisis dan membandingkan keuntungan serta kelayakan usaha dodol pada berbagai varian rasa yang diproduksi oleh UD. Wana Sari per bulan. Manfaat dari hasil penelitan ini diharapkan dapat digunakan sebagai masukan atau pertimbangan oleh UD. Wanasari dalam menentukan kelayakan suatu usaha

\section{METODE PENELITIAN}

Penelitian yang dilaksanakan di UD. Wanasari di Desa Suranadi, Kecamatan Narmada Kabupaten Lombok Barat, merupakan penelitian studi kasus, yaitu suatu penelitian yang menelaah suatu permasalahan yang menghusus pada suatu objek atau permasalahan tertentu yang bertujuan secara khusus menjelaskan dan memahami objek yang ditelitinya secara khusus sebagai suatu kasus. (Winarno Surakhmad, 2004, Sugyono, 2014).

Pemilihan lokasi secara sengaja ( purposive sampling ) dengan pertimbangan bahwa pada UD. Wanasari, memiliki masalah tentang kelayakan usaha dan diberikan ijin untuk melaksanakan penelitian. Teknik pengumpulan data yang digunakan adalah dengan observasi, wawancara dan dokomentasi, sedangkan alat yang digunakan adalah kuistioner

Variabel, definisi variabel dan cara pengukurannya dapat dijelaskan sebagai berikut :

1. Produksi dodol adalah jumlah produksi yang dihasilkan UD. Wanasari yang dihitung dalam bungkus/ bulan,

2. Harga produksi dodol adalah nilai dari suatu produk yang diukur dengan uang dalam Rp/bungkus

3. Nilai penerimaan (nilai produksi) dodol adalah jumlah produksi dodol dikalikan harga yang berlaku pada saat itu dalam Rp/bungkus/bulan

4. Biaya produksi dodol adalah semua korbanan (pengeluaran) yang dikeluarkan selama satu bulan baik biaya variabel maupun biaya tetap dalam Rp/bungkus /bulan

5. Keuntungan dodol adalah selisih antara penerimaan dengan semua biaya yang dikeluarkan dalam Rp/bungkus/bulan

6. Kelayakan usaha adalah suatu ukuran yag digunakan apakah usaha tersebut menguntungkan dan efisien apa tidak

Data yang dikumpulkan terlebih dahulu disusun, dijelaskan dibandingkan dan kemudian dianalisis. Dengan hasil analisis tersebut kemudian ditarik suatu kesimpulan, secara deskriptif

Analisis data yang digunakan dalam penelitian ini adalah :

\section{a. Biaya Usaha}

(TC) usahatani kedelai digunakan rumus : $\mathrm{TC}=\mathrm{FC}+\mathrm{VC}$

Keterangan : TC : Total Cost/biaya total, FC : Biaya Tetap, VC : Biaya Variabel

\section{b. Penerimaan}

Untuk menghitung total penerimaan (TR)

Penerimaan dodol digunakan rumus : TR $=\mathrm{Py}$. Y

Keterangan : TR : Total Revenue (Total Penerimaan), Py : Harga per satuan hasil produksi , y : Jumlah Produksi

\section{c. Keuntungan}

Untuk menghitung keuntungan digunakan rumus : $\pi=\mathrm{TR}-\mathrm{TC}$

Keterangan : $\pi=$ keuntungan, TR : total Penerimaan, TC : total Biaya

Kriteria :

Apabila : $\quad \mathrm{TR}=\mathrm{TC}=$ break event point (tidak untung dan tidak rugi $=$ titik pulang pokok)

$$
\begin{aligned}
& \mathrm{TR}>\mathrm{TC}=\text { untung } \\
& \mathrm{TC}<\mathrm{TC}=\text { rugi }
\end{aligned}
$$




\section{d. Kelayakan usaha (Soekartawi, 2006)}

\section{Nilai $\mathbf{R} / \mathbf{C}$}

Keterangan :

$$
\mathrm{R} / \mathrm{C}=\mathrm{TR}-\mathrm{TC}
$$

$\mathrm{TR}=$ Total revenue $($ Penerimaan $)=$ jumlah produksi dikalikan dengan harga per unit

$\mathrm{TC}=$ total cost (total biaya)

$\mathrm{R} / \mathrm{C}>1$, dikatakan layak,

$\mathrm{R} / \mathrm{C}=0$, dikatakan pulang pokok (break Even point) yaitu tidak untung dan tidak rugi. $\mathrm{R} / \mathrm{C}=1$, dikatakan rugi

2. $\mathbf{B} / \mathrm{C}$

B/C Ratio (Benefit Cost Ratio) adalah ukuran perbandingan antara pendapatan bersih atau keuntungan $($ Benefit $=$ B) dengan Total Biaya produksi $($ Cost $=$ C). (Bambang Riyanto, 1997) Rumusnya adalah sebagai berikut :

$$
\mathrm{B} / \mathrm{C}=\pi / \mathrm{TC}
$$

Keterangan :

$\pi=$ keuntungan, $\mathrm{TC}=$ total biaya

Jika $\mathrm{B} / \mathrm{C}$ ratio $>1$, usaha layak dilaksanakan,

jika $\mathrm{B} / \mathrm{C}$ ratio $<1$, bisnis tidak layak atau merugi

\section{Break Event Point}

Break event point atau keadaan pulang pokok adalah suatu analisis untuk menentukan dan mencari jumlah barang atau jasa yang harus dijual kepada konsumen pada harga tertentu untuk menutupi biayabiaya timbul serta mendapatkan keuntungan. Atau suatu teknik analisis untuk mempelajari hubungan antara biaya, keuntngan dan volume kegiatan (Bambang Riyanto, 1999)

Menurut Husein Umar (2005), keadaan pulang pokok merupakan keadaan dimana penerimaan pendapatan perusahaan sama dengan total biaya yang dikeluarkan oleh perusahaan

Dalam penelitian rumus yang digunakan untuk menghitung BEP (Bambang Riyanto, 1999):

$\operatorname{BEP}(\mathrm{Q})=\frac{F C}{\text { 㐸 }-V C / \text { unit }}$

Dimana : $\mathrm{P}=$ Harga Jual per Unit, $\mathrm{VC}=$ Biaya Variabel per Unit,

$\mathrm{FC}=$ Biaya Tetap, $\mathrm{Q}=$ Jumlah unit/kualitas produk yang dihasilkan dan dijual

Perhitungan Break Even Point (BEP) atas dasar penjualan dalam rupiah, formulanya adalah sebagai berikut:

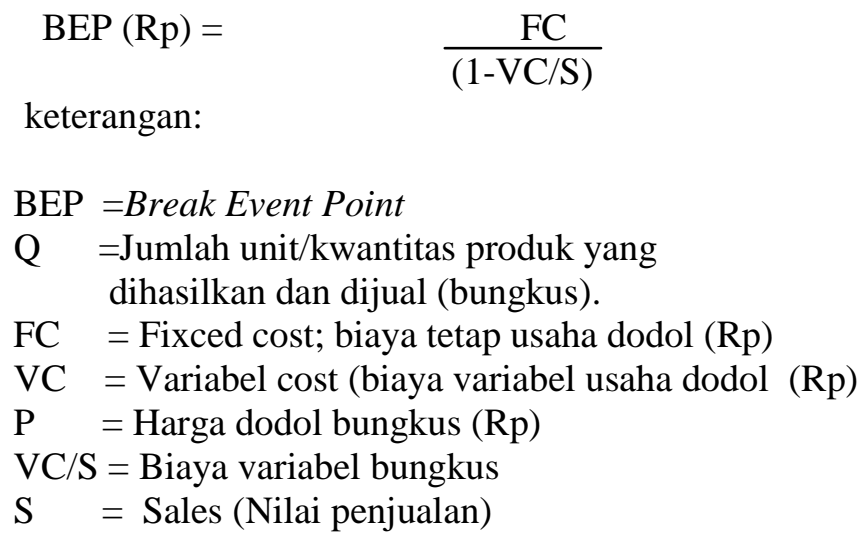




\section{HASIL DAN PEMBAHASAN}

\section{Biaya Produksi}

Tabel 2. Biaya Produksi Agroindustri Dodol Pada berbagai Varian Rasa

di UD. Wanasari dalam Sebulan Tahun 2019

\begin{tabular}{|c|c|c|c|c|c|c|}
\hline \multirow[t]{2}{*}{ No } & \multirow[t]{2}{*}{ Macam Biaya } & \multicolumn{5}{|c|}{ Varian Rasa } \\
\hline & & Nangka & Sirsak & Pisang & Durian & Ketan hitam \\
\hline \multicolumn{7}{|c|}{ Biaya Variabel $(V C)$} \\
\hline 1 & Bahan Baku & 2.000 .000 & $1.200 ., 000$ & 2.640 .000 & 2.560 .000 & 1.200 .000 \\
\hline 2 & Bahan Penolong & 940.000 & 940,080 & 1.034 .000 & 944.000 & 1.640 .000 \\
\hline 3 & Tenaga Kerja & 2.140 .000 & 1.857 .140 & 2.042 .854 & 1.485 .712 & 3.000 .000 \\
\hline 4 & Lain -lain & 1.234 .000 & 812.000 & 893.200 & 537.600 & 672.000 \\
\hline 5 & Sub Jumlah VC & 6.314 .000 & 4.809 .220 & 6.610 .054 & 5.527.312 & 6.512 .000 \\
\hline \multicolumn{7}{|c|}{ Biaya Tetap $(F C)$} \\
\hline \multirow[t]{3}{*}{1} & Penyusutan & 318.500 & 382.200 & 467.126 & 254.800 & 424.660 \\
\hline & Sub Jumlah FC & 318,500 & 382,200 & 467.126 & 254.800 & 424.660 \\
\hline & Total $(\mathrm{VC}+\mathrm{FC})$ & 6.632.500 & 5.191 .420 & 7.077 .180 & 5.782 .112 & 6.936 .660 \\
\hline
\end{tabular}

Sumber : Data Primer Diolah (2020)

Tabel di atas menunjukkan bahwa biaya produksi per bulan yang paling besar dikeluarkan pada agroindustri dodol adalah biaya produksi pada varian dodol rasa pisang yaitu Rp.7.077.180,- selama satu bulan. Kemudian disusul oleh biaya produksi varian dosol rasa ketan hitam, nangka, durian dan yang terkecil adalah rasa sirsak sebesar Rp.5.191.420 per bulan.

Besar kecil biaya produksi yang dikeluarkan pada berbagai varian rasa, selain disebabkan oleh besar kecilnya biaya bahan baku dan penolong yang dikeluarkan juga disebabkan oleh perbedaan jumlah hari produksi dalam sebulan. Rata-rata hari proses produksi dalam sebulan usaha dodol nangka, sirsak dan ketan hitam sebanyak 20 hari, sedangkan dodol durian sebanyak 16 hari dan dodol pisang rata-rata hari berproduksi sebanyak 22 hari. Banyak sedikitnya hari kerja, tergantng pada tersedianya bahan baku dan jumlah permintaan. Semakin banyak hari dan jumlah permintaan dodol, maka menyebabkan semakin banyak bahan baku, bahan penolong, tenaga kerja, biaya lain-lain dan nilai penyusutan yang dikeluarkan, sehingga akan berdampak pula pada semakin banyak biaya produksi yang dikeluarkan per bulannya.

\section{Produksi dan Nilai Produksi}

Tabel 3. Produksi dan Nilai Produksi Dodol Berbagai Varian Rasa Pada UD.Wanasari dalam Sebulan Tahun 2019

\begin{tabular}{|c|l|r|c|}
\hline Nomor & Varian rasa & Produksi (Mika) & Nilai Produksi (Rp) \\
\hline 1 & Nangka & 1.440 & 10.080 .000 \\
\hline 2 & Sirsak & 960 & 6.720 .000 \\
\hline 3 & Pisang & 1.210 & 8.470 .000 \\
\hline 4 & Durian & 768 & 6.528 .000 \\
\hline 5 & Ketan hitam & 1.200 & 8.400 .000 \\
\hline
\end{tabular}

Sumber : Data Primer Diolah (2020)

Pada Tabel 3 dapat ditunjukkan bahwa perbedaan nilai produksi, disamping ditentukan oleh jumlah produksi dalam per harinya, juga ditentukan oleh proses produksi dalam sebulan. Adanya perbedaan hari dalam proses produksi dodol menyebabkan juga jumlah produksi dan nilai produksi juga berbeda.

\section{Keuntungan Agroindustri Dodol}

Tabel 4. Keuntungan Agroindustri Dodol pada Berbagai Varian Rasa Dirinci Menurut Nilai Produksi, Biaya Produksi per Bulan pada UD.Wanasari Suranadi Tahun 2019

\begin{tabular}{|l|l|c|c|c|}
\hline No & \multicolumn{1}{|c|}{ Varian Rasa } & Nilai Produksi (Rp) & Biaya Produksi (Rp) & Keuntungan (Rp) \\
\hline 1 & Nangka & 10.080 .000 & 6.632 .500 & 3.447 .500 \\
\hline 2 & Sirsak & 6.720 .000 & 5.191 .420 & 1.528 .580 \\
\hline 3 & Pisang & 8.470 .000 & 7.077 .180 & 1.392 .820 \\
\hline 4 & Durian & 6.528 .000 & 5.782 .112 & 745.888 \\
\hline 5 & Ketan Hitam & 8.400 .000 & 6.936 .660 & 1.463 .340 \\
\hline
\end{tabular}

Sumber : Data Primer Diolah (2020) 
Tabel 4 terlihat bahwa keuntungan yang paling tinggi diperoleh per bulan adalah varian dodol rasa nangka yaitu Rp. 3.447.500,- Kemudian berturut-turut diikuti oleh keuntungan varian dodol rasa sirsak, ketan hitam, pisang dan keuntungan yang paling kecil diperoleh adalah usaha dodol varian rasa durian yaitu sebesar Rp. 745.888/ bulan

Besar kecilnya keuntungan yang diperoleh ditentukan oleh dua faktor yaitu faktor pertama adalah Nilai produksi dan faktor kedua adalah biaya produksi. Semakin besar nilai produksi dengan biaya yang rendah, maka keuntungannya akan tinggi dan sebaliknya keuntungan akan rendah jika nilai produksi yang rendah dengan jumlah biaya yang tinggi.

Nilai produksi ditentukan oleh jumlah produksi dan harga produksi. Semakin besar jumlah produksi yang disertai dengan harga yang tinggi, maka nilai produksinya akan tinggi dan sebaliknya, jika jumlah produksi yang kecil dan harga juga rendah, nilai produksinya akan rendah, atau kedua-duanya yang rendah baik jumlah produksi dan harga yang rendah. Jumlah produksi ditentukan oleh rata-rata berproduksi dalam sebulan.

\section{Kelayakan Agroindustri Dodol}

Kelayakan adalah suatu ukuran sebagai pertimbangan bagi pengusaha apakah suatu usaha itu dapat dilaksanakan dengan memberikan keuntungan, efisien dan dapat dikembangkan atau dilanjutkan.

Dalam penelitian ini kelayakan usaha agroindustri dodol pada berbagai varian di UD.Wanasari Desa Suranadi dianalisis dengan menggunakan Return Cost Ratio (R/C), Benefit Cost Ratio (B/C) dan Break Event Point (BEP)

Tabel 5. Kentungan Agroindustri Dodol pada Berbagai varian pada UD. Wanasari per bulan Tahun 2019

\begin{tabular}{|r|l|r|r|r|r|r|}
\hline No & Uraian & \multicolumn{5}{|c|}{ Varian dodol } \\
\hline & & Nangka & \multicolumn{1}{|c|}{ Sirsak } & \multicolumn{1}{c|}{ Pisang } & \multicolumn{1}{c|}{ Durian } & Ketan Hitam \\
\hline 1 & Produksi (mika) & 1.440 & 960 & 1.210 & 768 & 1.200 \\
\hline 2 & Nilai Produksi (Rp) & 10.080 .000 & 6.720 .000 & 8.470 .000 & 6.528 .000 & 8.400 .000 \\
\hline & Biaya-biaya & & & & & \\
\hline 3 & Biaya Variabel (Rp) & 6.314 .000 & 4.809 .220 & $6.610,054$ & 5.527 .312 & 6.512 .000 \\
\hline 4 & $\begin{array}{l}\text { Biaya variabel /mika } \\
\text { Rp) }\end{array}$ & $4.384,720$ & 5.010 & $6.259,520$ & $7.197,021$ & $5.426,667$ \\
\hline 5 & Biaya tetap (Rp) & 318.500 & 382.200 & 467.126 & 254.800 & 424.660 \\
\hline 6 & Total Biaya (Rp) & 6.632 .500 & 5.191 .420 & $7.077,180$ & 5.782 .112 & 6.936 .660 \\
\hline 7 & Keuntungan (Rp) & 3.447 .500 & 1.528 .580 & $1.392,820$ & 745.888 & 1.463 .340 \\
\hline
\end{tabular}

Sumber : Data Primer Diolah (2020)

Tabel 6. Rata-Rata Keuntungan dan Kelayakan Usaha per Bulan pada Agroindustri Dodol pada Berbagai Varian Rasa di UD.Wanasari Tahun 2019

\begin{tabular}{|l|l|c|c|c|c|c|c|}
\hline No & Varian Rasa & Keuntungan & \multirow{2}{*}{ R/C } & \multirow{2}{*}{ B/C } & \multicolumn{2}{|c|}{ BEP } & \multirow{2}{*}{ Ket } \\
\cline { 5 - 7 } & & & & & Mika & Rupiah & \\
\hline 1 & Nangka & 3.447 .500 & 30,45 & 10,40 & 121,8 & $508.470,07$ & Untung dan layak \\
\hline 2 & Sirsak & 1.528 .580 & 25,89 & 5,89 & 192 & 534.054 & Untung dan layak \\
\hline 3 & Pisang & 1.392 .820 & 26,33 & 4,33 & 303,82 & 598.567 & Untung dan layak \\
\hline 4 & Durian & 745.888 & 18,06 & 2,06 & 195,52 & 300.930 & Untung dan layak \\
\hline 5 & Ketan Hitam & 1.463 .340 & 24,22 & 4,22 & 270 & 547.780 & Untung dan layak \\
\hline
\end{tabular}

Sumber : Data Primer Diolah (2020)

Dari tabel tersebut dapat dijelskan sebagai berikut :

1. Rata-rata keuntungan yang diperoleh usaha dodol varian rasa nangka per bulan sebesar Rp. 3.447.500, dengan perolehan $\mathrm{R} / \mathrm{C}=30,45, \mathrm{~B} / \mathrm{C}=10,24$, dengan titik impas (BEP volume) sebanyak 121,8 mika dan BEP nilai penjualan sebesar Rp. 508.470,07

2. Rata-rata keuntungan yang diperoleh usaha dodol varian rasa sirsak per bulan sebesar Rp. 1.528.580 dengan perolehan $\mathrm{R} / \mathrm{C}=25,89, \mathrm{~B} / \mathrm{C}=5,89$, dengan titik impas ( $\mathrm{BEP}$ volume) sebanyak 192 mika dan BEP nilai penjualan sebesar Rp. 534.054

3. Rata-rata keuntungan yang diperoleh usaha dodol varian rasa pisang per bulan sebesar Rp. 1.392.820, dengan perolehan $\mathrm{R} / \mathrm{C}=26,33, \mathrm{~B} / \mathrm{C}=4,33$, dengan titik impas (BEP volume) sebaanyak 303,82 mika dan BEP nilai penjualan sebesar Rp. 598.567 
4. Rata-rata keuntungan yang diperoleh usaha dodol varian rasa durian per bulan sebesar Rp. 745.888 dengan perolehan $\mathrm{R} / \mathrm{C}=18,06, \mathrm{~B} / \mathrm{C}=2,06$, dengan titik impas (BEP volume) sebanyak 195,52 mika dan BEP nilai penjualan sebesar Rp. 300.930

5. Rata-rata keuntungan yang diperoleh usaha dodol varian rasa ketan hitam per bulan sebesar Rp. 1.463.340 dengan perolehan $\mathrm{R} / \mathrm{C}=24,22, \mathrm{~B} / \mathrm{C}=4,22$, dengan titik impas (BEP volume) sebanyak 270 dan BEP nilai penjualan sebesar Rp. 547.780

Jika dilihat dari keuntungan, $\mathrm{R} / \mathrm{C}$ dan $\mathrm{B} / \mathrm{C}$, maka usaha dodol varian rasa nangka yang paling tinggi keuntungannya, dan paling besar $\mathrm{R} / \mathrm{C}$ dan $\mathrm{B} / \mathrm{C}$ nya, sehingga paling layak untuk diusahakan. Kemudian berturut-turut diikuti oleh dodol varian rasa : sirsak, ketan hitam, pisang dan rasa durian.

\section{PENUTUP}

\section{Simpulan}

Dari hasil penelitian dapat disimpulkan bahwa : agroindustri dodol yang paling besar keuntungannya dan layak untuk diusahakan per bulannya adalah agroindustri dodol varian rasa nangka, dengan keuntungan rata-rata yang diperoleh per bulan sebesar Rp. 3.447.500, dan perolehan $\mathrm{R} / \mathrm{C}=30,45, \mathrm{~B} / \mathrm{C}=10,24$, lebih tinggi dari usaha dodol varian yang lain dengan titik impas (BEP volume) sebanyak 121,8 mika dan BEP nilai penjualan sebesar Rp. 508.470,07

\section{Saran}

Varian dodol semua rasa menguntungkan dan layak diusahakan, disarankan kepada UD. Wanasari, Desa Suranadi Kecamatan Narmada Kabupaten Lombok agar tetap membuat dodol dengan berbagai varias rasa, untuk menarik minat konsumen berbelanja ke usaha dagang tersebut.

\section{DAFTAR PUSTAKA}

Kartika Ngamel, A (2015). Analisis Usaha dan Nilai Tambah Pengolahan Dodol Rumput Laut Skala Rumah Tangga di Desa Loon, Kecamatan Kei Kecil, Kabupaten Maluku Tenggara. Jurnal Sains Terapan Edisi V Vol-5 (1) : 40 - 49. http//journal.ipb.ac/index.php/jstsu/article/journal. Diakses pada 2 Maret 2020.

Kasmir dan Jakfar. (2010). Studi Kelayakan Bisnis. Jakarta: Kencana Prenada Media Group.

Maryati, S. (2001). Pembuatan Dodol Nangka dalam Rangka Usaha diversivikasi Produksi Olahan Dodol. Berita Litbang Industri hal 2

Nafarin, M. (2009). Biaya Produksi. Dalam http.www.pelajaran.co.id. Diakses tanggal 1 April 2020

Riyanto, B. (1999). Dasar-dasar Pembelanjaan. Yogyakarta: Yayasan Badan Penerbit Gajah Mada.

Soekartawi. (2006). Analisis Usahatani. Jakarta: Penerbit Universitas Indonesia

Gyska. (2014). Produksi Dodol. Dalam Repositori.upi.edu. Diakses tanggal 1 Pebruari 2020

Sugiyono. (2015). Metode Penelitian Pendidikan Pendekatan Kuantitatif, Kualitatif, dan R\&D. Bandung: Alfabeta.

Sultan. (2017). Analisis Kelayakan Usaha Baje Dodol KUB IK Cipta Usaha Kelurahan Anreapi Kecamatan Anreapi Kabupaten Polewali Mandar. Jurnal Agrovital: Jurnal Ilmu Pertanian Universitas Al Asyariah Vol 2, No 2017.

Surakhmad, W. (2004). Teknik, Metode Penelilitian. Bandung: Tarsito Bandung

Umar, H. (2005). Studi Kelayakan Bisnis. Jakarta: Gramedia Pustaka

Widyastuti. (1993). Pengembangan Bisnis Dodol Nangka. https//eprints.unram.ac.id diakses tanggal 30 Maret 2020 